\title{
Social Media Activism and Kerala Culture
}

Tony Isaac Luke

Assistant Professor

Deva Matha College

Kuravilangad, Kerala, India

tonyisaacluke@gmail.com

First there was newspaper, and then came television. And now it's the advent of the internet. Granted it has been over two decades since its arrival, but its potential was not realized until about 2005, when the youngsters began to revel in the wonders of social media. Orkut, Facebook, Google Plus, Instagram, Pinterest, Tumblr and WhatsApp are a few social media websites and mobile applications that have managed to captivate a large number of followers.

Such sites and applications have also been of use in getting the message out there. In earlier days the main method of involving a large audience in a particular event was to take an advertisement in a newspaper. But in the present tech-savvy world of ours, a simple e-vite is enough to bring together a massive crowd. By putting up an event in Facebook, one could easily pull together enough spectators to make any affair a success.

In present Kerala, a major movement is taking place among the online community in Facebook, WhatsApp, etc. Social media activism has become a substantial part of the average Malayalis day-to-day life. Troll pages on Facebook like Troll Malayalam, International Chalu Union-ICU, Troll Republic-TR, etc are responsible for bringing to its followers the many news stories that our regular daily newspapers recoil from. These troll creators or trollans as they are known in our society are mostly youngsters who are either in college or are in the pursuit of a job. Labelled jobless by the society whose faults they bring to light, 
these trollans work using Photoshop or other image editors with no reward in sight. Through this paper, I plan to shed light on how social media activism works in the present Kerala society and how our society regards it by focusing on a few instances of Facebook activism.

WhatsApp, Facebook, Messenger, Twitter, Instagram, Pinterest, etc., are a few of the most popular messaging and social networking applications used by the present world. Facebook leads with over 2 Billion users, followed closely by Messenger and WhatsApp with over a billion users each. As of 2017, the daily social media usage of global internet users amounted to 135 minutes per day, up from 126 daily minutes in 2016. Each citizen of the global world spends a large part of his life inside online media.

According to a recent report by Common Sense Media, 75 percent of teenagers in America currently have profiles on social networking sites, of which 68 percent use Facebook as their main social networking tool. It is true that social networking does play a vital role in broadening social connections and helps in learning technical skills. But we simply cannot overlook the risks associated with it. The lack or difficulty in self-regulation and susceptibility to peer pressure makes adolescents vulnerable to such evils as Facebook depression, sexting, and cyber bullying, which are realistic threats. Other problems that can probably occur are social network-induced obesity, internet addiction and sleep deprivation which are serious issues that need to be effectively managed.

Facebook with its 2 billion followers leads the social networking field, and is filled with a large number of fake users for the purpose of anonymity. The Telegraph reported 'Around two-to-three per cent of its 2.1 billion monthly users in the third quarter of 2017 were "user-misclassified and undesirable accounts", Facebook said'; which comes up to over 270 million accounts. Last year The Hindu reported'India overtakes US as Facebook’s no.1 user' with over 241 million users. It is still unclear as to the number of fake accounts in any of its states. 
But as anyone who has a Facebook profile in Kerala, and is a member of any troll group can attest to, the number of fake Facebook profiles among Keralites are definitely on the rise. Social media activism is fad for today's Malayali. Regardless of whether his comments might be true or not, he repeatedly posts under a fake name for any cause that he deems important. There are a lot of cyber protectors of faith, sex and politics within the Keralite online community. These online soldiers feel it is their duty to bring to the public the various news items that the official news houses do not publish. Since they have next to zero fear of repercussions, they post any status regarding items that they feel are of international, national, or local importance.

Dealing with subjects from food habits to class X marks, these trollans bring to the general public various news items that most national media news outlets are sometimes paid to overlook. The problem arises when the trollans are asked for verification of their sources. While newspapers have a source credibility check for the most part, such clarifications are not necessary on the part of online journalists or such cyber activists. All they believe is that society should come to know of events that are hidden from them, sometimes even deliberately.

One such event, which barely crossed the minds of millions of Indians, till December of last year, when it was brought to the public eye, was the story of a young man named Sreejith who had been protesting for over 700 days demanding justice for his brother Sreejeev, who died while in police custody. The young man had been on a sit-in strike on the pavement girdling the Secretariat in Trivandrum for nearly two years demanding justice for his brother, who had died in police custody in Kerala in 2014.

In May 2014, Parassala police of Trivandrum district in Kerala had taken Sreejeev into custody for the theft of 13 mobile phones. Days later he died at the Medical College Hospital, Trivandrum. While police officials maintain that Sreejeev consumed poison, his 
family accused the officers of murder and cited custodial torture as the reason for his death. The State Police Complaints Authority held a preliminary probe and found that Parassala Circle Inspector Gopakumar and Additional Sub-Inspector Philipose guilty. But the detailed police investigation was unable to find any evidence of custodial torture.

The government ordered a CBI probe, following the allegations. But the CBI, after collecting all the primary details seemed in a dilemma. According to Sreejith, they were not sure whether to take over the investigation or not. It was at this point that that he decided to start a protest against the government so that the murderers of his brother would be brought to justice. Sreejith decided to sit on strike until the government acknowledged his demands. From May of 2015, Sreejith started his one-man fight against the state government of Kerala; a fight which a few local news stations brought to the public domain briefly in 2015. Later, in February, 2017, The NEWS Minute published an article '430 days and counting: Kerala man awaits justice for brother who died in police custody'. Again there came a deafening silence on the part of the media.

Finally in 12 January 2018, again the news broke of Sreejith's struggle for justice. Immediately there began a torrent of online support for his cause. Keralites from all over the world began to declare their solidarity to Sreejith by outing up \#JusticeForSreejith statuses in Facebook. Troll pages in Facebook like ICU-International Chalu Union, Troll Malayalam, Troll Republic, etc were filled with pictures of Sreejith along with images of movie screenshots. His struggle for justice had become a cause for the online Malayali community.

This was the same community that bestowed the choicest abuses on Maria Sharapova for being unaware of Sachin Tendulkar. Troll users filled Facebook with their creative contributions regarding this issue. This online movement went on strong till $14^{\text {th }}$ January. On Sunday, $14^{\text {th }}$ January, youngsters from various districts in Kerala flocked to the Secretariat building in the state capital of Trivandrum. The roads were filled with a huge procession of 
ordinary folk who had gathered to show their support for a common youngster who was fighting his personal battle. This was a huge milestone in Kerala history because till this point all such processions or gatherings were done on the basis of political allegiances. This protest was unique for its wide participation regardless of the people's personal political affiliations. Also, it was a gathering a much of Kerala's youth which were considered wastrels. This was a collective that took a decision that this was a struggle which required their actual physical presence, and not merely a support in the form of a hash tag sign. The streets of the capital were filled with a colorful gang of young Keralites who had come together for one man. This was a struggle unique for its participation.

The online community whole heartedly took up his struggle and started their fight for his cause. This was the first protest of this kind in Kerala, probably even in India. After all the elite media houses arrived to capture the event, and made it a successful protest, the Chief minister of Kerala, Shri Pinarayi Vijayan, was left with no choice but to involve the CBI into the matter. This struggle was taken up then by the major celebrities of Kerala in the political, cultural and sports arenas of Kerala. Movie stars, political leaders, singers and football players joined this struggle to show how they were one with Sreejith and that his cause was now theirs too.

But we cannot say that all such Facebook or online campaigns are just or even necessary. I am of course talking about the recent feminichi issue where a few Malayalam movie actors were harassed on social media by fans of another Malayalam movie actor for expressing her opinions about the latter's film Kasaba. The word feminichi is a derogatory term meaning a radical feminist, which became part of the Malayalam vocabulary after the Malayalam movie actor Parvathy expressed her views on sexism in Malayam movies. At a discussion on women in cinema at the International Film Festival of Kerala (IFFK) in Thiruvananthapuram in December 2017, national award winning actor Parvathy had said, "I 
was definitely disappointed to watch an actor par excellence ... say certain dialogues which were not only derogatory but most saddening to a woman... When the hero says it, it gives a licence for many other men to do the same..."

Though the remark was intended not to insult anyone, but more as a reproach for choosing the role of a sexist police officer, fans of veteran actor megastar Mammooty took outrage at how anyone could even put-down their beloved ' $I k k a$ '. Over the next few weeks, the full extent of the wrath of the actor's fan base in Kerala became clear to everyone as Parvathy's social media accounts on Twitter, Facebook and Instagram were flooded with hateful, abusive and threatening messages.

The fans' antagonism towards Parvathy rests on the so-called audacity of a newcomer challenging a veteran actor like Mammootty. While most fans feel that a contemporary criticizing the actor is tolerable, advice from a comparatively young actor is strictly out of bounds. The cyber fans of the megastar did not stop with just mere abuses. 'My Story' is an upcoming Malayalam film directed and produced by Roshni Dinaker, written by Shankar Ramakrishnan and starring Prithviraj Sukumaran and Parvathy in the lead roles. A video song "Pathungi" from the movie was released on 31 December prior to the movie's release and at present the song has over 160,000 dislikes on YouTube. Online fans of Mammootty ensured that the song video got as many dislikes as possible as a warning that the movie would receive even worse reception and reviews.

Rima Kallingal was the next Malayalam movie actress who was affected by the same online abuse. While this entire hullabaloo was happening, a TedX video of Malayalam movie actor Rima Kallingal started making its rounds. "When I joined the Malayalam film industry, I heard words like shelf life, adjust, compromise, smile more. We girls are always asked to dumb down. And we are so good at putting up an act - becoming someone that society wants us to be," she said at TedX talk in Thiruvananthapuram in October 2017. She even mentioned 
the circumstances of her becoming a feminist when she saw the disparity of a fried fish being served to her grandmother, father and brother, while she and her mother were not considered deserving of the fish fry.

This video was suddenly catapulted into the forefront of various Facebook pages and was immediately commented upon by many Keralites. Without wasting much time, troll pages like Troll Malayalam, International Chalu Union-ICU, and Troll Republic-TR were filled with images of how even a fish could be the reason for a woman becoming a feminist. The virtual world had turned against another actor who was caught in a battle that she was losing badly. Things took a turn for the worst when fans of Mammootty threatened to boycott the film "Mayanadhi" directed by Aashik Abu, a self-confessed feminist and the husband of Rima Kallingal, who has always been a crusader against sexism in cinema and society.

The terrible ordeal that these two women had to go through is deplorable. The fact that it happened in a state that boasts of $95 \%$ literacy rate is shocking. Being educated is not to be equated with being a human being anymore. The hard truth is that such incidents are no longer isolated events. Online abuse and harassment is never easy to deal with since most of the time, one is unaware who the attacker is. The virtual world offers a safe place more for the abuser than the victim. It is high time that we realize that these heinous acts should not be part our society and culture. Even if there are moments where just causes like Sreejith's are taken up, we should always remember that judicious use of social networking sites and applications is of the utmost importance. 


\section{Works Cited}

Ameerudheen, TA. "766 Days and Counting: A Man's Fight for Justice for His Dead Brother Has Caught Kerala's Attention.” Scroll.in, Https://Scroll.in, 15 Jan. 2018, scroll.in/article/865177/766-days-and-counting-a-mans-fight-for-justice-for-his-deadbrother-has-caught-keralas-attention.

Anand, G. "The Social Effect on Sreejith's Solitary Struggle.” The Hindu, 20 Jan. 2018, www.thehindu.com/news/national/the-social-effect-on-sreejiths-solitarystruggle/article22481359.ece.

Balan, Saritha S. "The One Man Battle Which Shook Kerala - A Look Back at Sreejith's Two Year Long Protest.” The News Minute, 2 Feb. 2018, www.thenewsminute.com/article/one-man-battle-which-shook-kerala-look-backsreejith-s-two-year-long-protest-75752.

"Demanding Justice, A Brother Has Been Sitting In Front Of Kerala Secretariat Every Day For Last 2 Years.” The Logical Indian, 4 Jan. 2018, thelogicalindian.com/news/kerala-man-battles-for-his-brother-protests-2-years-infront-of-secretariat-continues-struggle/.

Ians. "India Overtakes US as Facebook's No. 1 User.” The Hindu, 14 July 2017, www.thehindu.com/sci-tech/technology/internet/india-overtakes-us-as-facebooks-no1-user/article19276683.ece.

"International Chalu Union - ICU." Facebook - Log In or Sign Up, www.facebook.com/InternationalChaluUnion/.

Megha Varier Follow@varier_megha."Yes, Fish Fry Is Relevant to Feminism: Why Rima Kallingal's TedX Talk Is Bang On.” The News Minute, 18 Jan. 2018, www.thenewsminute.com/article/yes-fish-fry-relevant-feminism-why-rima-kallingalstedx-talk-bang-74899. 
MeghaVarier Follow@varier_megha. “430 Days and Counting: Kerala Man Awaits Justice for Brother Who Died in Police Custody." The News Minute, 15 Jan. 2018, www.thenewsminute.com/article/430-days-and-counting-kerala-man-awaits-justicebrother-who-died-police-custody-57214.

"My Story | Pathungi HD Video Song | Prithviraj Sukumaran, Parvathy RoshniDinaker." YouTube, YouTube, 31 Dec. 2017, www.youtube.com/watch?v=zAJ-66acp4M.

Nagarajan, Saraswathy. "Fans Let Loose War of Words in Mollywood." The Hindu, 21 Dec. 2017, www.thehindu.com/society/women-in-malayalam-cinema-speak-up-againsttrolls/article22134686.ece.

Prakash, Asha. "Tovino Has the Perfect Reply for 'Feminichi Trolls' - Times of India.” The Times of India, The Times of India, 24 Dec. 2017, timesofindia.indiatimes.com/entertainment/malayalam/movies/news/tovino-has-theperfect-reply-for-feminichi-trolls/articleshow/62230387.cms.

Ramasubbu, Suren. "Influence of Social Media on Teenagers.” The Huffington Post, TheHuffingtonPost.com, 26 May 2015, www.huffingtonpost.com/surenramasubbu/influence-of-social-media-on-teenagers_b_7427740.html.

TNM Staff Follow @thenewsminute. “Facebook Admits It Has Whopping 270 Million Fake and Duplicate Accounts.” The News Minute, 4 Nov. 2017, www.thenewsminute.com/article/facebook-admits-it-has-whopping-270-million-fakeand-duplicate-accounts-71069.

TNM Staff Follow @thenewsminute. “'How Long Do We Dumb down?': Rima Kallingal's TedX Talk on Sexism in Malayalam Cinema.” The News Minute, 15 Jan. 2018, www.thenewsminute.com/article/how-long-do-we-dumb-down-rima-kallingal-s-tedxtalk-sexism-malayalam-cinema-74772.

“Troll Republic - TR.” Facebook - Log In or Sign Up, www.facebook.com/TrollRepublic/. 
“Troll Malayalam.” Facebook - Log In or Sign Up, www.facebook.com/TrollMalayalamOfficial/.

Varma, Vishnu. "Who Is Afraid of a Feminichi?" The Indian Express, 28 Jan. 2018, indianexpress.com/article/express-sunday-eye/mammootty-parvathy-kasaba$5040577 /$. 